\title{
TAMANHO DE AMOSTRA PARA A ESTIMATIVA DAS MÉDIAS DECENDIAIS DE RADIAÇÃO SOLAR GLOBAL NO ESTADO DO RIO GRANDE DO SUL
}

\author{
Sample size for estimating the ten-day averages of global solar radiation in \\ Rio Grande do Sul State, Brazil
}

\author{
Alberto Cargnelutti Filho ${ }^{1}$, Ronaldo Matzenauer ${ }^{2}$, Jaime Ricardo Tavares Maluf ${ }^{3}$, \\ Bruna Pires da Silva ${ }^{4}$
}

\begin{abstract}
RESUMO
Com o objetivo de verificar a variabilidade temporal e espacial do tamanho de amostra da radiação solar global média decendial, de 22 locais do Estado do Rio Grande do Sul, utilizaram-se séries de dados de radiação solar global do período de 1956 a 2003. Determinou-se o tamanho de amostra da radiação solar global média decendial em cada decêndio e local e agruparam-se os decêndios e os locais pelo método hierárquico 'vizinho mais distante'. Há variabilidade do tamanho de amostra (número de anos) para a estimativa da radiação solar global média decendial no Estado do Rio Grande do Sul no tempo e no espaço. Maior tamanho é necessário nos decêndios dos meses de junho, julho, agosto e setembro em relação aos outros meses. Para os locais e decêndios estudados, 30 anos de observações são suficientes para estimar a média $(\mu)$ de radiação solar global média decendial, para um erro de estimação igual a $0,123 \hat{\mu}$, com coeficiente de confiança de $95 \%$.
\end{abstract}

Termos para indexação: Amostragem, variabilidade temporal e espacial, estatística inferencial.

\begin{abstract}
With the aim of verifying the temporal and spatial variability of the sample size ten-day average of the global solar radiation of 22 locations of Rio Grande do Sul State, Brazil, the global solar radiation data were collected from 1956 to 2003. One determined the sample size in each ten-day and location by clustering it using the complete linkage method. Results show that there is variability in the sample size of the ten-day average global solar radiation in Rio Grande do Sul State both in temporal and spatial scale. Greater sample size is necessary in the ten-day of June, July, August and September in relation to the others. For the studied locations and ten-day, 30 years of data are enough to predict the global solar radiation average $(\mu)$, for an error estimation equal to $12.3 \%$ average interval, with a reliable degree of $95 \%$.
\end{abstract}

Index terms: Sampling, spatial and temporal variability, inferential statistics.

(Recebido em 3 de outubro de 2006 e aprovado em 29 de março de 2007)

\section{INTRODUÇÃO}

A radiação solar global pode ser definida como o total de energia emitida pelo sol, que incide sobre a superfície terrestre, com comprimento de onda compreendido entre 150 e $4.000 \mathrm{~nm}$ (ROSENBERG, 1974; SLATER, 1980). É um elemento meteorológico de grande importância, principalmente em atividades agropecuárias. Assim, é importante medir a disponibilidade de radiação solar global em um determinado local e período do ano.

A média estimada a partir de um determinado número de observações (anos) tem sido uma medida comumente utilizada para isso. No entanto, a média desacompanhada de uma medida de variabilidade dos dados (amplitude, desvio-padrão, variância e coeficiente de variação) é insuficiente para inferir sobre a confiabilidade de tais estimativas.

A obtenção de todos os elementos de uma população possibilita calcular os parâmetros populacionais de uma variável, com ausência de erro. Porém a disponibilidade de tempo, de mão-de-obra, de dados e de recursos financeiros e humanos, dificulta a realização deste processo, necessitando estimar o parâmetro populacional por meio de medições realizadas em um determinado número de elementos da população (amostra). Fica evidente, que a estimativa obtida a partir de uma amostra está associada a um erro. No entanto, processos de amostragem são utilizados a fim de definir a amostra cuja estimativa seja o mais próximo possível do parâmetro

\footnotetext{
'Engenheiro Agrônomo, Doutor, Professor Adjunto - Departamento de Estatística/DEST - Universidade Federal do Rio Grande do Sul/UFRGS - Avenida Bento Gonçalves, 9500, Bairro Agronomia - 91509-900 - Porto Alegre, RS - cargnelutti@ufrgs.br

'Engenheiro Agrônomo, Doutor, Pesquisador - Centro de Meteorologia Aplicada - Fundação Estadual de Pesquisa Agropecuária/FEPAGRO - Rua Gonçalves Dias, 570, Bairro Menino Deus - 90130-060 - Porto Alegre, RS - ronaldo-matzenauer@fepagro.rs.gov.br - Bolsista do CNPq ${ }^{3}$ Engenheiro Agrônomo, Mestre, Pesquisador - Centro de Meteorologia Aplicada - Fundação Estadual de Pesquisa Agropecuária/FEPAGRO - Rua Gonçalves Dias, 570, Bairro Menino Deus - 90130-060 - Porto Alegre, RS - jaime-maluf@fepagro.rs.gov.br ${ }^{4}$ Graduanda em Agronomia - Departamento de Ciências Exatas - Universidade Estadual Paulista/UNESP - Rodovia Professor Donato Castellane, Km 5 14884-900 - Jaboticabal, SP - brunapires-santa@hotmail.com
} 
populacional. Conjuntos de dados com pouca variabilidade podem ser representados por uma menor amostra quando comparados a um grupo de dados heterogêneos.

Trabalhos de ajustes de função de distribuição de probabilidade e/ou estimativas de probabilidade usando funções de distribuição de probabilidade teóricas, em relação à radiação solar (BURIOL et al., 2000, 2001; CARGNELUTTI FILHO et al., 2004) têm sido desenvolvidos, enfatizando, de maneira geral, os benefícios de tais estudos no planejamento de atividades que minimizem riscos climáticos. Estudos de tamanho de amostra para a estimativa da temperatura máxima (CARGNELUTTI FILHO et al., 2006b) e mínima do ar média mensal (CARGNELUTTI FILHO et al., 2006a) no Estado do Rio Grande do Sul, mostraram variabilidade do tamanho de amostra (número de anos) no tempo (meses) e no espaço (locais). Maior tamanho de amostra para a estimativa da temperatura máxima é necessário nos meses de maio, junho, julho e agosto e para a estimativa da temperatura mínima é necessário nos meses de maio, junho e julho (CARGNELUTTI FILHO et al., 2006a,b). Porém, estudos de tamanho de amostra, relacionados à radiação solar global, são pouco conhecidos no Estado do Rio Grande do Sul. Assim, é importante determinar o tamanho de amostra (número de anos) necessário para estimar a média $\left(\mu\right.$ ) de radiação solar global média decendial em cal cm${ }^{-2} \mathrm{dia}^{-1}$, com confiabilidade, levando-se em consideração a variabilidade temporal e espacial de uma região.

Ao determinar o tamanho de amostra, em um determinado local e época do ano, é preciso estabelecer um erro máximo aceitável com um determinado coeficiente de confiança. No entanto, não há um valor de radiação solar global média decendial em cal $\mathrm{cm}^{-2} \mathrm{dia}^{-1}$ que possa ser definido como erro máximo tolerável. Assim, neste estudo, utilizou-se um erro máximo tolerável na estimativa da média $\left(\mu\right.$ ) de radiação solar global média decendial em cal cm${ }^{-2} \mathrm{dia}^{-1}$ de $0,10 \hat{\mu}$ com coeficiente de confiança $(1-\alpha)$ de $95 \%$. É evidente que o tamanho de amostra aumenta com a diminuição do erro permitido, com o acréscimo do coeficiente de confiança e com o aumento da variabilidade dos dados.

Objetiva-se com este trabalho verificar a variabilidade temporal e espacial do tamanho de amostra para a estimativa de radiação solar global média decendial de vinte e dois locais do Estado do Rio Grande do Sul.

\section{MATERIAL E MÉTODOS}

Os dados de radiação solar global das vinte e duas estações agrometeorológicas, oriundos de locais do Estado do Rio Grande do Sul, foram obtidos do Banco de Dados do Centro de Meteorologia Aplicada, da Fundação Estadual de Pesquisa Agropecuária Fepagro/SCT-RS (Tabela 1) e coletados no período de 1956 a 2003. Em cada local e ano, com os dados diários de radiação solar global, calculou-se a radiação solar média decendial, em cal $\mathrm{cm}^{-2} \mathrm{dia}^{-1}$, de cada um dos 36 decêndios do ano, formando 792 séries temporais (22 locais x 36 decêndios) com número diferenciado de anos de observações em cada série em função da disponibilidade de dados meteorológicos (Tabela 1).

Aplicou-se o teste de Bartlett (STEEL et al., 1997) nos dados de radiação solar global média decendial, para verificar a homogeneidade das variâncias, entre os decêndios do ano (36 variâncias - variabilidade temporal), em cada local (22 testes) e entre os locais (22 variâncias variabilidade espacial) em cada um dos 36 decêndios do ano (36 testes).

Calculou-se o tamanho de $\operatorname{amostra}(\eta)$, de cada uma das 792 séries de dados (36 decêndios x 22 locais) de radiação solar global média decendial, para uma semiamplitude do intervalo de confiança igual a $10 \%$ da estimativa da média $(\mu)$ de radiação solar global média decendial, em cal cm${ }^{-2} \mathrm{dia}^{-1}$, com coeficiente de confiança de $95 \%$, pela expressão $\eta=\frac{t_{\alpha / 2}^{2} S^{2}}{\text { erro }^{2}}$ (BARBETTA et al., 2004; BUSSAB \& MORETTIN, 2004; COSTA-NETO, 2002; FONSECA \& MARTINS, 1995; MUNIZ \& ABREU, 1999; SPIEGEL et al., 2004), na qual: erro é a semiamplitude do intervalo de confiança (10\% de $\hat{\mu})$ e $t_{\alpha / 2}$ é o valor da distribuição $t$ de Student cuja área à direita é igual a $\alpha / 2$, isto é, é o valor de t tal que: $\mathrm{P}\left(\mathrm{t}>\mathrm{t}_{\alpha / 2}\right)=\alpha / 2$, com $(\mathrm{n}-1)$ graus de liberdade e $\alpha=$ $5 \%$ de probabilidade de erro e $\mathrm{S}^{2}$ é a variância amostral. O tamanho de amostra $(\eta)$ foi estimado iterativamente até sua convergência.

A partir do tamanho de amostra, em cada decêndio e local do Estado do Rio Grande do Sul, determinaram-se as matrizes de distância euclidiana média padronizada entre os 36 decêndios e entre os 22 locais, que foram utilizadas como medida de dissimilaridade para a análise de agrupamento dos decêndios e dos locais, respectivamente, pelo método hierárquico 'vizinho mais distante' (CRUZ \& REGAZZI, 1997). 
TABELA 1 - Período observado e valor calculado da estatística do teste de Bartlett $\left(\chi_{\text {calc }}^{2}\right)$ das variâncias, de radiação solar global média decendial, de cada decêndio entre os locais e das variâncias de cada local entre os 36 decêndios do ano.

\begin{tabular}{|c|c|c|c|c|c|c|c|c|}
\hline \multicolumn{4}{|c|}{ Local } & \multirow[t]{2}{*}{ Período } & \multirow{2}{*}{$\chi_{\text {calc }}^{2}$} & \multirow[t]{2}{*}{ Mês } & \multirow[t]{2}{*}{ Dec } & \multirow{2}{*}{$\chi_{\text {calc }}^{2}$} \\
\hline Nome & Altitude (m) & Latitude (S) & Longitude (W) & & & & & \\
\hline Alegrete & 96 & $29^{\circ} 46^{\prime} 59^{\prime \prime}$ & $55^{\circ} 46^{\prime} 59^{\prime \prime}$ & $1968-2001$ & $104,30 * *$ & Janeiro & 1 & $67,23 * *$ \\
\hline Cachoeirinha & 4 & $29^{\circ} 57^{\prime} 36^{\prime \prime}$ & $51^{\circ} 04^{\prime} 22^{\prime}$, & $1975-2002$ & $125,82 * *$ & Janeiro & 2 & $62,14 * *$ \\
\hline Caxias do Sul & 787 & $29^{\circ} 10^{\prime} 25^{\prime \prime}$ & $51^{\circ} 12^{\prime} 21^{\prime \prime}$ & $1987-2003$ & $95,41 * *$ & Janeiro & 3 & $71,24 * *$ \\
\hline Cruz Alta & 473 & $28^{\circ} 38^{\prime} 21^{\prime}$ & $53^{\circ} 36^{\prime} 34^{\prime \prime}$ & 1974-1998 & $108,88^{* *}$ & Fevereiro & 1 & $44,47 * *$ \\
\hline Encruzilhada do Sul & 420 & $30^{\circ} 32^{\prime} 35^{\prime}$, & $52^{\circ} 31^{\prime} 20^{\prime \prime}$ & 1958-1999 & $101,47 * *$ & Fevereiro & 2 & $61,42 * *$ \\
\hline Erechim & 760 & $27^{\circ} 37^{\prime} 46^{\prime \prime}$ & $52^{\circ} 16^{\prime} 33^{\prime \prime}$ & 1966-1991 & $90,86 * *$ & Fevereiro & 3 & $51,06 * *$ \\
\hline Farroupilha & 702 & $29^{\circ} 14^{\prime} 30^{\prime \prime}$ & $51^{\circ} 26^{\prime} 20^{\prime \prime}$ & 1963-1996 & $114,25 * *$ & Março & 1 & $77,08 * *$ \\
\hline Ijuí & 448 & $28^{\circ} 23^{\prime} 17^{\prime}$ & $53^{\circ} 54^{\prime} 50^{\prime \prime}$ & 1963-1990 & $105,92 * *$ & Março & 2 & $51,86^{* *}$ \\
\hline Júlio de Castilhos & 514 & $29^{\circ} 13^{\prime} 26^{\prime \prime}$ & $53^{\circ} 40^{\prime} 45^{\prime \prime}$ & $1956-1996$ & $198,49 * *$ & Março & 3 & $42,95 * *$ \\
\hline Maquiné & 32 & $29^{\circ} 40^{\prime} 49^{\prime \prime}$ & $50^{\circ} 13^{\prime} 56^{\prime \prime}$ & $1957-1997$ & $145,15^{* *}$ & Abril & 1 & $42,40 * *$ \\
\hline Passo Fundo & 709 & $28^{\circ} 15^{\prime} 41^{\prime}$ & $52^{\circ} 24^{\prime} 45^{\prime \prime}$ & $1961-2003$ & $147,14 * *$ & Abril & 2 & $35,65^{*}$ \\
\hline Quaraí & 100 & $30^{\circ} 23^{\prime} 17^{\prime \prime}$ & $56^{\circ} 26^{\prime} 53^{\prime \prime}$ & $1966-2000$ & $80,35 * *$ & Abril & 3 & $50,81 * *$ \\
\hline Rio Grande & 15 & $32^{\circ} 01^{\prime} 44^{\prime \prime}$ & $52^{\circ} 15^{\prime} 37^{\prime \prime}$ & 1956-1997 & $242,71 * *$ & Maio & 1 & $64,44 * *$ \\
\hline Santa Maria & 95 & $29^{\circ} 41^{\prime} 25^{\prime \prime}$ & $53^{\circ} 48^{\prime} 42^{\prime \prime}$ & $1965-1998$ & $112,40 * *$ & Maio & 2 & $58,00 * *$ \\
\hline Santa Rosa & 273 & $27^{\circ} 51^{\prime} 50^{\prime}$ & $54^{\circ} 29^{\prime} 03^{\prime \prime}$ & 1975-1999 & $51,76^{*}$ & Maio & 3 & $41,98 * *$ \\
\hline Santana do Livramento & 210 & $30^{\circ} 53^{\prime} 18^{\prime}$, & $55^{\circ} 31^{\prime} 56^{\prime \prime}$ & $1965-1981$ & $78,63 * *$ & Junho & 1 & $44,22 * *$ \\
\hline São Borja & 99 & $28^{\circ} 39^{\prime} 44^{\prime}$, & $56^{\circ} 00^{\prime} 15^{\prime}$ & $1956-2000$ & $118,01 * *$ & Junho & 2 & $34,42 *$ \\
\hline São Gabriel & 109 & $30^{\circ} 27^{\prime} 27^{\prime}$ & $54^{\circ} 19^{\prime} 01^{\prime \prime}$ & $1963-2000$ & $143,77 * *$ & Junho & 3 & $41,19 * *$ \\
\hline Taquari & 76 & $29^{\circ} 48^{\prime} 15^{\prime \prime}$ & $51^{\circ} 49^{\prime} 30^{\prime \prime}$ & $1963-2000$ & $130,91 * *$ & Julho & 1 & $37,62 *$ \\
\hline Uruguaiana & 74 & $29^{\circ} 45^{\prime} 23^{\prime \prime}$ & $57^{\circ} 05^{\prime} 12^{\prime \prime}$ & 1963-1991 & $66,60 * *$ & Julho & 2 & $39,20 * *$ \\
\hline Vacaria & 955 & $28^{\circ} 30^{\prime} 09^{\prime \prime}$ & $50^{\circ} 56^{\prime} 12^{\prime \prime}$ & 1966-1990 & $96,50 * *$ & Julho & 3 & $46,37 * *$ \\
\hline \multirow[t]{15}{*}{ Veranópolis } & 705 & $28^{\circ} 56^{\prime} 14^{\prime \prime}$ & $51^{\circ} 33^{\prime} 11^{\prime \prime}$ & 1956-1999 & $96,93 * *$ & Agosto & 1 & $30,63^{\mathrm{ns}}$ \\
\hline & & & & & & Agosto & 2 & $30,47^{\mathrm{ns}}$ \\
\hline & & & & & & Agosto & 3 & $55,03 * *$ \\
\hline & & & & & & Setembro & 1 & $29,28^{\mathrm{ns}}$ \\
\hline & & & & & & Setembro & 2 & $27,76^{\mathrm{ns}}$ \\
\hline & & & & & & Setembro & 3 & $36,00 *$ \\
\hline & & & & & & Outubro & 1 & $36,39 *$ \\
\hline & & & & & & Outubro & 2 & $24,93^{\mathrm{ns}}$ \\
\hline & & & & & & Outubro & 3 & $57,83^{* *}$ \\
\hline & & & & & & Novembro & 1 & $40,88^{* *}$ \\
\hline & & & & & & Novembro & 2 & $52,77 * *$ \\
\hline & & & & & & Novembro & 3 & $70,15^{* *}$ \\
\hline & & & & & & Dezembro & 1 & $52,46 * *$ \\
\hline & & & & & & Dezembro & 2 & $70,30 * *$ \\
\hline & & & & & & Dezembro & 3 & $68,42 * *$ \\
\hline
\end{tabular}

*,** significativo a $5 \%$ e $1 \%$, respectivamente, pelo teste de Bartlett. ${ }^{\text {ns }}=$ Não-significativo. 
A partir da expressão utilizada para o cálculo do tamanho de amostra $\left(\eta=\frac{\mathrm{t}_{\alpha / 2}^{2} \mathrm{~S}^{2}}{\text { erro }^{2}}\right)$ fixou-se $\eta$ em 30 anos de observações (média histórica) e calculou-se o erro (precisão) em percentagem da estimativa da média $(\mu)$ de radiação solar global média decendial, para cada decêndio e local, pela expressão erro $=\frac{t_{\alpha / 2} S}{\sqrt{n} \hat{\mu}} \times 100$. As análises foram realizadas com o auxílio da planilha eletrônica Office Excel e do programa Genes (CRUZ, 2001).

\section{RESULTADOS E DISCUSSÃO}

As variâncias entre os 36 decêndios, em cada local, foram heterogêneas $(p \leq 0,05)$ em todos os locais, indicando tamanho de amostra diferenciado entre os decêndios (Tabela 1) e evidenciando presença de variabilidade temporal do tamanho de amostra de radiação solar global média decendial e possibilidade de agrupar os decêndios.

Entre as variâncias dos 22 locais, em cada decêndio, o teste de Bartlett (STEEL et al., 1997) revelou variâncias homogêneas em cinco decêndios, evidenciando que o tamanho da amostra para estimar a radiação solar global média decendial pode ser a mesma para os 22 locais nesses decêndios. No entanto, nos demais 31 decêndios $(86,11 \%)$ as variâncias entre locais foram heterogêneas $(p \leq 0,05)$, revelando a necessidade de estimar o tamanho de amostra em cada local. Isso permite inferir a presença de variabilidade espacial e possibilidade de agrupar os locais.

O tamanho de amostra para a estimativa de radiação solar global média decendial, em cada decêndio e local, com semi-amplitude do intervalo de confiança igual a $10 \%$ da estimativa da média $(\mu)$ de radiação solar global média decendial, em cal cm $\mathrm{cm}^{-2} \mathrm{dia}^{-1}$, e coeficiente de confiança de $95 \%$, oscilou de seis anos no $1^{\circ}$ decêndio do mês de março em Vacaria e no $3^{\circ}$ decêndio do mês de novembro em Santana do Livramento e Uruguaiana a 46 anos no $1^{\circ}$ decêndio do mês de setembro em Maquiné (Tabela 2). Portanto, em relação ao $1^{\circ}$ decêndio do mês de março em Vacaria e ao $3^{\circ}$ decêndio do mês de novembro em Santana do Livramento e Uruguaiana, pode-se inferir com 95\% de confiança que o intervalo de confiança da média $(\mu)$ de radiação solar global média decendial obtida com seis anos de observações é $\mu \pm 0,10 \hat{\mu} \mathrm{cal} \mathrm{cm}^{-2} \mathrm{dia}^{-1}$. Em outro extremo, a precisão de $\mu \pm 0,10 \hat{\mu} \mathrm{cal} \mathrm{cm}^{-2} \operatorname{dia}^{-1}$ é obtida com 46 anos de observações, em relação ao $1^{\circ}$ decêndio do mês de setembro em Maquiné. Esses resultados confirmam a variabilidade existente entre decêndios dentro dos locais (temporal) e entre locais dentro de decêndios (espacial). Então, 46 anos de observações forneceriam estimativas de radiação solar global média decendial, com $95 \%$ de confiabilidade de que o erro máximo é $0,10 \hat{\mu} \mathrm{cal} \mathrm{cm}^{-2} \mathrm{dia}^{-1}$, independentemente do decêndio e local.

De maneira geral, maior tamanho de amostra é necessária nos meses de junho, julho, agosto e setembro, diminuindo gradativamente em direção a janeiro e dezembro, indicando maior e menor variabilidade, respectivamente (Tabela 2 e Figura 1). Maiores valores de radiação solar global média decendial no Estado do Rio Grande do Sul (CARGNELUTTI FILHO et al., 2004), ocorreram, de maneira geral, em janeiro e dezembro, diminuindo em direção aos meses de junho e julho. Portanto, pode-se inferir que há relação inversamente proporcional entre a radiação solar global média decendial e o tamanho de amostra (número de anos). Resultados semelhantes em relação ao tamanho de amostra para a estimativa da temperatura máxima e mínima do ar média mensal no Estado do Rio Grande do Sul foram obtidos por (CARGNELUTTI FILHO et al., 2006a,b).

Utilizando-se $70 \%$ de similaridade, como critério para definição dos grupos pelo método hierárquico do vizinho mais distante, houve formação de três grupos de decêndios com comportamento similar dentro do grupo e divergente entre grupos. Treze decêndios $\left(2^{\circ}\right.$ decêndio de março, $3^{\circ}$ decêndio de março,..., $1^{\circ}$ decêndio de março) compuseram o grupo um, caracterizado por decêndios com menor variabilidade de radiação solar global média decendial entre os anos, necessitando menor tamanho de amostra (números de anos) para estimar a radiação solar global média decendial (Figura 1). Em outro extremo, seis decêndios $\left(2^{\circ}\right.$ decêndio de agosto, $2^{\circ}$ decêndio de setembro,..., $1^{\circ}$ decêndio de julho) compuseram o grupo três, caracterizado por maior tamanho de amostra, portanto maior variabilidade. Os demais 17 decêndios formaram um grupo intermediário (grupo dois). Estes resultados confirmam presença de variabilidade temporal do tamanho de amostra e, a necessidade de considerar número diferenciado de anos de observação para estimar a radiação solar global média decendial. Portanto, ao usar o mesmo número de anos para estimar a radiação solar global média decendial, a precisão da estimativa dos seis decêndios que compuseram o grupo três é menor em relação aos demais decêndios do ano (Tabela 3). 
TABELA 2 - Tamanho de amostra (número de anos) para a estimativa da média ( $\mu$ ) de radiação solar global média decendial em localidades do Estado do Rio Grande do Sul com 95\% de confiança e semi-amplitude do intervalo de confiança de $0,10 \hat{\mu} \mathrm{cal} \mathrm{cm}^{-2} \mathrm{dia}^{-1}$.

\begin{tabular}{|c|c|c|c|c|c|c|c|c|c|c|c|c|c|c|c|c|c|c|c|c|c|c|c|c|}
\hline \multirow[b]{2}{*}{ 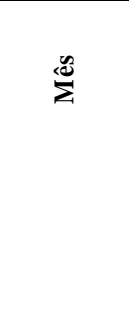 } & \multirow[b]{2}{*}{ 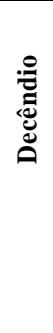 } & \multicolumn{22}{|c|}{ Local } & \multirow[b]{2}{*}{ 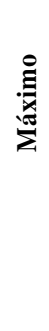 } \\
\hline & & 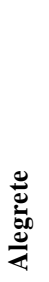 & 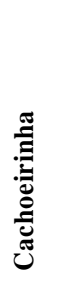 & 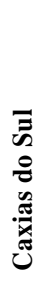 & 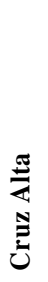 & 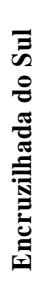 & 志 & 胥 & 帠 & 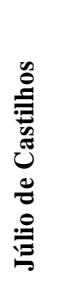 & 兰 & 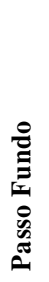 & 预 & 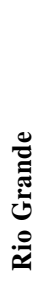 & 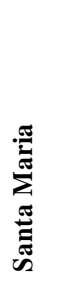 & 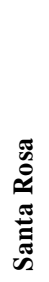 & 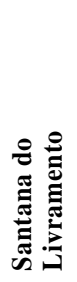 & 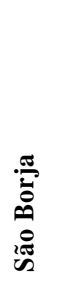 & 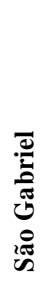 & $\underset{\Xi}{\stackrel{\Xi}{\Xi}}$ & 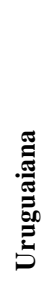 & 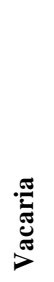 & 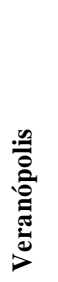 & \\
\hline Janeiro & 1 & 14 & 10 & 9 & 10 & 16 & 24 & 11 & 15 & 27 & 25 & 8 & 15 & 21 & 11 & 10 & 10 & 14 & 9 & 8 & 8 & 11 & 13 & 27 \\
\hline Janeiro & 2 & 19 & 13 & 11 & 17 & 15 & 29 & 17 & 22 & 29 & 27 & 11 & 15 & 22 & 13 & 14 & 9 & 13 & 8 & 10 & 8 & 12 & 14 & 29 \\
\hline Janeiro & 3 & 7 & 13 & 15 & 19 & 15 & 22 & 12 & & 2 & & 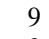 & 12 & & 14 & 7 & 15 & 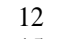 & 10 & 0 & 12 & & 2 & 28 \\
\hline Fevereiro & 1 & 9 & 17 & 21 & 15 & 15 & 18 & 12 & 10 & 22 & 18 & 8 & 13 & 22 & 13 & 13 & 1 & 15 & 15 & 8 & 10 & 8 & 11 & 22 \\
\hline Fevereiro & 2 & 17 & 11 & 8 & 12 & 26 & 19 & 13 & 18 & 32 & 28 & 9 & 14 & 22 & 18 & 15 & 15 & 19 & 12 & 12 & 9 & 11 & 12 & 32 \\
\hline Fevereiro & 3 & 11 & 15 & 15 & 30 & 19 & 23 & 19 & 29 & 30 & 29 & 14 & 16 & 39 & 22 & 14 & 13 & 18 & 15 & 12 & 8 & 16 & 14 & 39 \\
\hline Março & 1 & 12 & 10 & 14 & 14 & 12 & 8 & 13 & 10 & 31 & 23 & 8 & 18 & 16 & 11 & 13 & 10 & 19 & 9 & 8 & 14 & 6 & 9 & 31 \\
\hline Março & 2 & 11 & 11 & 11 & 21 & 17 & 21 & 18 & 16 & 30 & 26 & 12 & 15 & 17 & 13 & 14 & 12 & 14 & 9 & 14 & 11 & 17 & 14 & 30 \\
\hline Março & 3 & 10 & 10 & 11 & 14 & 19 & 20 & 16 & 18 & 25 & 27 & 11 & 18 & 22 & 14 & 15 & 11 & 15 & 10 & 13 & 11 & 14 & 18 & 27 \\
\hline Abril & 1 & 8 & 15 & 15 & 24 & 18 & 19 & 19 & 26 & 24 & 25 & 11 & 10 & 17 & 13 & 13 & 10 & 22 & 15 & 11 & 17 & 16 & 15 & 26 \\
\hline Abril & 2 & 11 & 15 & 17 & 19 & 30 & 18 & 16 & 25 & 20 & 26 & 17 & 16 & 20 & 18 & 18 & 11 & 22 & 22 & 12 & 15 & 11 & 21 & 30 \\
\hline Abril & 3 & 11 & 14 & 25 & 25 & 19 & 17 & 18 & 26 & 22 & 31 & 14 & 17 & 18 & 22 & 15 & 12 & 18 & 11 & 14 & 13 & 7 & 14 & 31 \\
\hline Maio & 1 & 12 & 10 & 13 & 16 & 20 & 25 & 18 & 23 & 30 & 34 & 15 & 13 & 18 & 17 & 41 & 11 & 17 & 13 & 11 & 11 & 15 & 19 & 41 \\
\hline Maio & 2 & 16 & 9 & 10 & 18 & 24 & 23 & 15 & & 3 & & 13 & & & & 31 & & & & 15 & & 14 & 5 & 31 \\
\hline Maio & 3 & 15 & 13 & 12 & 17 & 24 & 17 & 19 & 22 & 31 & 34 & 10 & 20 & 27 & 20 & 24 & 11 & 16 & 17 & 13 & 19 & 12 & 14 & 34 \\
\hline Junho & 1 & 36 & 10 & 14 & 18 & 36 & 31 & 21 & 28 & 43 & 34 & 17 & 30 & 29 & 24 & 18 & 25 & 24 & 25 & 20 & 18 & 14 & 21 & 43 \\
\hline Junho & 2 & 2 & 16 & 12 & 29 & 27 & 19 & 17 & & 3 & & 15 & & & & 20 & & & & 15 & 9 & 5 & 1 & 35 \\
\hline Junho & 3 & 19 & 16 & 15 & 16 & 24 & 27 & 24 & 23 & 29 & 26 & 10 & 26 & 24 & 17 & 22 & 20 & 19 & 16 & 12 & 15 & 14 & 22 & 29 \\
\hline Julho & 1 & 17 & 16 & 24 & 30 & 28 & 20 & 17 & 35 & 35 & 27 & 15 & 26 & 38 & 19 & 39 & 37 & 20 & 22 & 14 & 18 & 19 & 28 & 39 \\
\hline Julho & 2 & 23 & 22 & 18 & 19 & 20 & 20 & 12 & 15 & 27 & 30 & 11 & 27 & 23 & 23 & 38 & 17 & 24 & 20 & 19 & 12 & 18 & 22 & 38 \\
\hline Julho & 3 & 16 & 20 & 11 & 20 & 27 & 24 & 14 & 21 & 35 & 20 & 11 & 32 & 21 & 19 & 24 & 20 & 17 & 16 & 18 & 17 & 16 & 20 & 35 \\
\hline Agosto & 1 & 29 & 23 & 15 & 26 & 37 & 23 & 20 & 26 & 31 & 38 & 13 & 28 & 39 & 26 & 32 & 21 & 20 & 22 & 17 & 16 & 18 & 25 & 39 \\
\hline Agosto & 2 & 14 & 31 & 16 & 19 & 26 & 24 & 29 & 23 & 29 & 40 & 18 & 17 & 18 & 21 & 36 & 22 & 17 & 13 & 23 & 15 & 17 & 28 & 40 \\
\hline Agosto & 3 & 9 & 20 & 9 & 17 & 20 & 20 & 15 & 22 & 38 & 35 & 12 & 12 & 29 & 20 & 26 & 14 & 20 & 14 & 17 & 11 & 13 & 20 & 38 \\
\hline Setembro & 1 & 14 & 20 & 17 & 16 & 34 & 14 & 24 & 31 & 35 & 46 & 14 & 18 & 32 & 19 & 31 & 14 & 22 & 22 & 26 & 30 & 17 & 23 & 46 \\
\hline Setembro & 2 & 24 & 18 & 14 & 19 & 20 & 32 & 28 & 30 & 35 & 36 & 17 & 19 & 26 & 18 & 24 & 12 & 17 & 21 & 16 & 19 & 23 & 25 & 36 \\
\hline Setembro & 3 & 16 & 14 & 25 & 32 & 20 & 16 & 31 & 26 & 32 & 24 & 17 & 13 & 2 & 20 & 22 & 9 & 19 & 13 & 18 & 15 & 10 & 17 & 32 \\
\hline Outubro & 1 & 20 & 15 & 12 & 20 & 15 & 19 & 14 & 23 & 25 & 23 & 11 & 17 & 19 & 18 & 15 & 26 & 12 & 19 & 11 & 5 & 17 & 18 & 26 \\
\hline Outubro & 2 & 8 & 14 & 19 & 20 & 17 & 15 & 15 & 19 & 16 & 28 & 14 & 9 & 16 & 16 & 17 & 12 & 13 & 14 & 11 & 12 & 19 & 17 & 28 \\
\hline Outubro & 3 & 7 & 13 & 14 & 18 & 23 & 15 & 17 & 13 & 23 & 29 & 10 & 10 & 26 & 16 & 12 & 13 & 13 & 11 & 9 & 10 & 15 & 21 & 29 \\
\hline Novembro & 1 & 13 & 16 & 18 & 20 & 16 & 18 & 10 & 26 & 26 & 32 & 10 & 15 & 24 & 18 & 19 & 16 & 15 & 18 & 13 & 14 & 9 & 21 & 32 \\
\hline Novembro & 2 & 12 & 8 & 12 & 16 & 11 & 11 & 11 & 13 & 16 & 31 & 7 & 11 & 23 & 13 & 9 & 10 & 14 & 12 & 8 & 9 & 10 & 16 & 31 \\
\hline Novembro & 3 & 7 & 10 & 14 & 10 & 14 & 14 & 9 & 19 & 22 & 29 & 9 & 11 & 20 & 9 & 18 & 6 & 11 & 9 & 10 & 6 & 8 & 11 & 29 \\
\hline Dezembro & 1 & 24 & 12 & 9 & 15 & 14 & 7 & 10 & 13 & 21 & 27 & 10 & 13 & 16 & 9 & 12 & 11 & 12 & 8 & 14 & 9 & 15 & 13 & 27 \\
\hline Dezembro & 2 & 8 & 7 & 9 & 11 & 12 & 15 & 13 & 12 & 22 & 21 & 9 & 10 & 19 & 10 & 9 & 9 & 12 & 7 & 7 & 7 & 7 & 15 & 22 \\
\hline Dezembro & 3 & 13 & 9 & 12 & 16 & 16 & 16 & 11 & 9 & 23 & 31 & 7 & 10 & 25 & 11 & 11 & 8 & 12 & 11 & 9 & 8 & 12 & 9 & 31 \\
\hline Máximo & & 36 & 31 & 25 & 32 & 37 & 32 & 31 & 35 & 43 & 46 & 18 & 32 & 39 & 26 & 41 & 37 & 24 & 25 & 26 & 30 & 23 & 28 & 46 \\
\hline
\end{tabular}

A formação de três grupos de locais foi possível pelo método hierárquico do vizinho mais distante, utilizando-se $50 \%$ de similaridade como critério para definição dos mesmos (Figura 2). Os 10 locais (Passo Fundo, Taquari, Vacaria, São Gabriel, Uruguaiana, Cachoeirinha, Caxias do Sul, Alegrete, Quarai e Santana do Livramento) que compuseram o grupo um são os locais com menor variabilidade de radiação solar global média decendial, necessitando menor tamanho de amostra (números de anos) para estimar a radiação solar global média decendial. Já os locais de Júlio de Castilhos, Maquiné e Rio Grande compuseram o grupo três, 


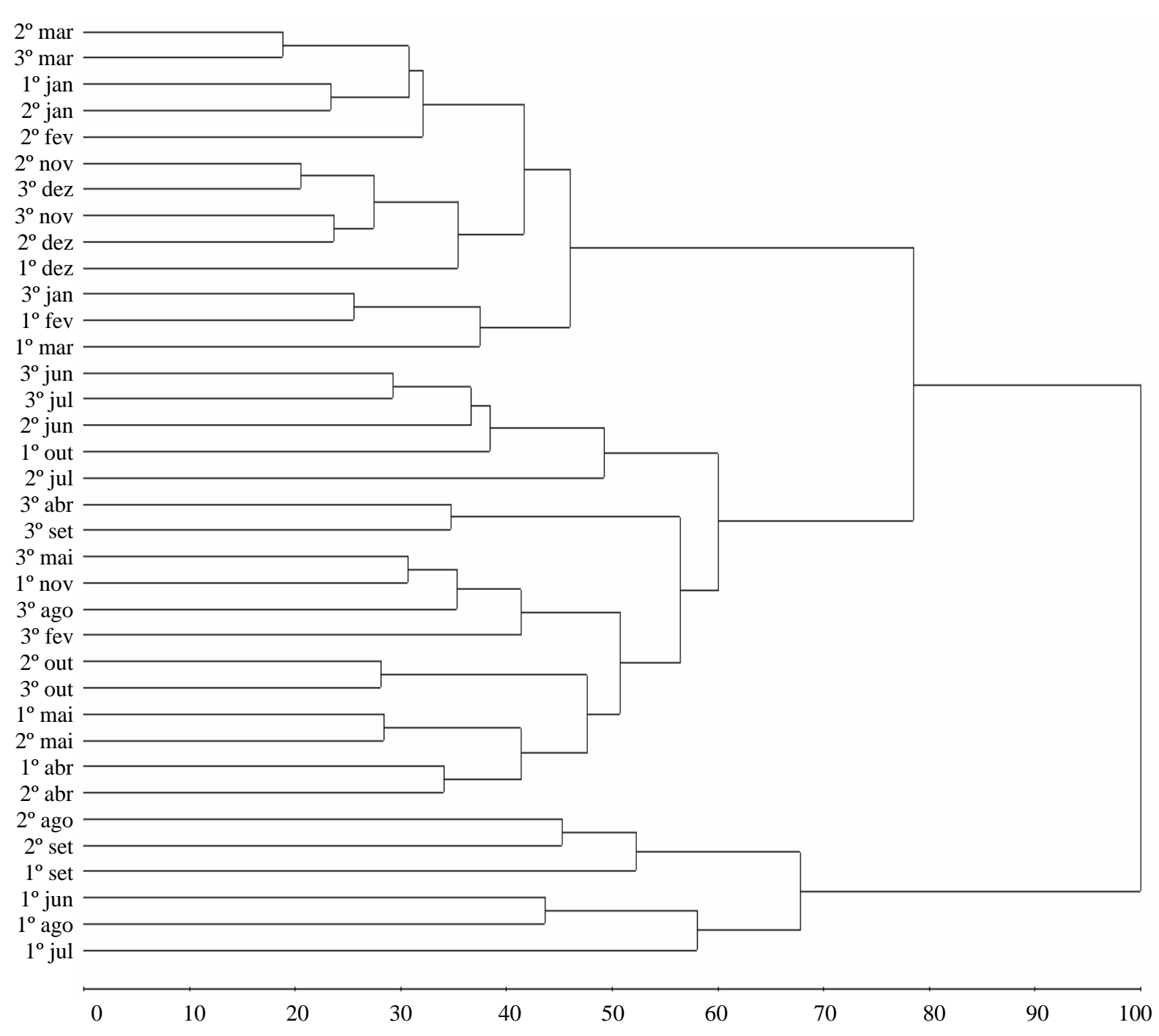

FIGURA 1 - Dendrograma da dissimilaridade, de radiação solar global média decendial, entre os decêndios do ano do Estado do Rio Grande do Sul, obtido pelo método de agrupamento "vizinho mais distante" baseado na distância euclidiana média padronizada. 
TABELA 3 - Semi-amplitude do intervalo de confiança em percentagem da estimativa da média $(\mu)$ de radiação solar global média decendial, em cal cm $\mathrm{cm}^{-2} \mathrm{dia}^{-1}$, baseado em 30 anos de observações em cada decêndio e local do Estado do Rio Grande do Sul.

\begin{tabular}{|c|c|c|c|c|c|c|c|c|c|c|c|c|c|c|c|c|c|c|c|c|c|c|c|c|}
\hline \multirow[b]{2}{*}{ 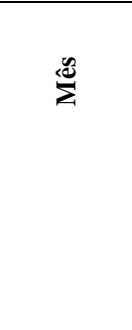 } & \multirow[b]{2}{*}{ 承 } & \multicolumn{22}{|c|}{ Local } & \multirow[b]{2}{*}{ 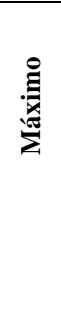 } \\
\hline & & 苞 & 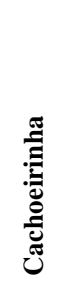 & 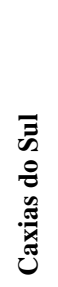 & 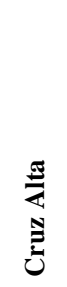 & 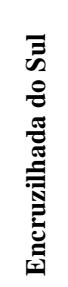 & 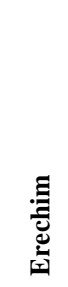 & 胥 & 河 & 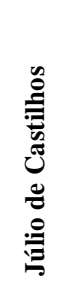 & $\begin{array}{l}\stackrel{\cdot}{\Xi} \\
\underset{\Xi}{\Xi} \\
\sum\end{array}$ & 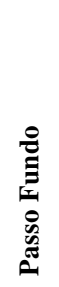 & 䔍 & 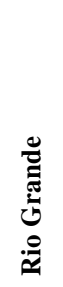 & 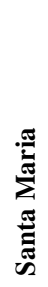 & 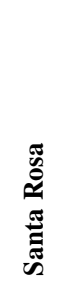 & 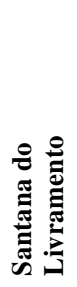 & 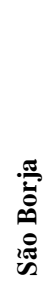 & 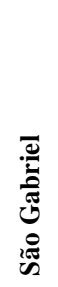 & 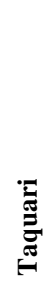 & 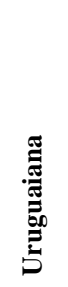 & 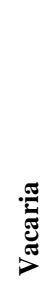 & 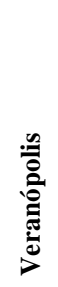 & \\
\hline ane & 1 & 6 & $\overline{5,2}$ & 4,7 & & & & & & & & & & & & & 5,2 & 6,2 & & & & 5,3 & & \\
\hline Janeiro & 2 & & 6,2 & 8 & 7 & & & & & & 9,2 & & & & & & & 5,9 & & & 2 & 5,8 & & 9 \\
\hline Janeiro & 3 & 4 , & 6,0 & 68 & 7 & & & 5,9 & 7 & 9 & 7,9 & 4 & & 9,5 & 6,3 & & 0 & 5,7 & 1 & & 5,8 & 4,2 & & 9,5 \\
\hline Fevereiro & 1 & 4, & 7,2 & 8,4 & 6,8 & & 7 & 5 & 5,2 & 8 & 7,2 & 4,4 & & 8,3 & & & & 6,7 & 6,5 & & 5,2 & 4,3 & 5,4 & 8,4 \\
\hline Fevereiro & 2 & 7 , & 5,4 & 4,4 & 5 , & & & & & 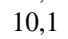 & 9,5 & 4, & & 8,4 & & & 1 & 7,7 & & & 4,7 & 5,6 & 5,9 & 10,1 \\
\hline evereiro & 3 & 5, & 6,7 & 6,9 & 10,0 & 7 & 8 & 7,6 & 10,0 & & 9,6 & 6 & 7,0 & 11,4 & & & & 7,4 & 6,5 & & 4,3 & 7,1 & 2 & 11,4 \\
\hline Março & 1 & 5 , & 4,9 & 6,7 & & & & 6,0 & & 1 & 8,5 & & & & & & & & & & & & & 10,1 \\
\hline Março & 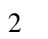 & 5 & 5,4 & 57 & & 7 & & & & & 9,1 & & & & & & & 2 & 4,7 & & 5,4 & 7,2 & & 9,8 \\
\hline Ma & 3 & 5 , & 4,9 & 5,7 & & 7 & & 6 & & & 9,3 & 5 & 7,3 & 8,3 & 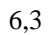 & 0 & 5 & 6,5 & 5,0 & & 5,6 & 6,4 & & 9,3 \\
\hline $\mathrm{Ab}$ & 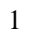 & 4, & 6,8 & 6,9 & & & & & & & 9,0 & & & & & & & & & & & & & 2 \\
\hline Abril & 2 & 5 , & 6,7 & 7,4 & 7 & 9 & 7 & 6,8 & 9 & 7,7 & 9,0 & 6 & & 7,8 & & 7, & & 8,3 & & & 6,7 & 5,7 & & 9,8 \\
\hline Abril & 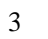 & 5 , & 6,3 & 9,3 & 9 & 7 & 7 & 7,4 & & 8 & 10,1 & 6 & 7 & 7,4 & 8 , & 6 & & 7,4 & 5,3 & & 6,1 & 4,0 & 6,3 & 10,1 \\
\hline Iaio & 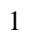 & 5 & 5,2 & 63 & & & & & & & 10,6 & & & 7,4 & & , & &, 1 & 6,1 & & 5,5 & 6,6 & 7,5 & 12,0 \\
\hline Maio & 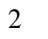 & 7 & 4,6 & 5 & & 8 & 8 & 6 & & 9 & 9,5 & 6 & & 7,0 & 8 & & & 8,1 & 4,8 & & 6,9 & 6,4 & 6 & 10,3 \\
\hline Maio & 3 & 6 , & 6,1 & 5,8 & & & & 7 & & & 10,6 & & & & & & & 6,8 & 7,1 & & 7,8 & 5,7 & 6,4 & 10,6 \\
\hline uho & 1 & 11 & 4,9 & 6,5 & 7,4 & 10,9 & 10,2 & 8 & 9,5 & 11,9 & 10,6 & 7,0 & 10,0 & 9,7 & & 7 & 9,5 & 7 & 9,0 & & 7,4 & 6,5 & 8,1 & 11,9 \\
\hline & 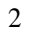 & & 6,9 & 5,9 & & & & & & & & & & & & & & 7,3 & 6,1 & & 7,8 & 6,7 &, 1 & 10,7 \\
\hline & 3 & & 7,0 & 7,0 & & & & & & & & & & & & & & 7,6 & & & 6,6 & 6,6 & 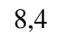 & 9,6 \\
\hline 10 & 1 & & 6,9 & 9,2 & 10,0 & & & 7,1 & 10,9 & 10,7 & 9,3 & 6 & 9,1 & 1,3 & 7,6 & 11,6 & 8 & 7,9 & 4 & & 7,6 & 7,7 & 6 & 11,8 \\
\hline & 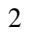 & & 8,4 & 7,7 & & & & & & & 9,8 & & & & & & & 8,6 & 7,7 & & & 7,5 & ,2 & 11,5 \\
\hline lho & 3 & & 8,0 & 5,4 & & & & & & & & 5 & & & & & & 7,0 & & & 7,3 & 6,9 & 7,9 & 10,7 \\
\hline Agosto & 1 & 10,1 & 8,6 & 6,9 & 9,2 & 11,0 & & 7,9 & 9,1 & 10,0 & 11,2 & 6,0 & 9,5 & 1,5 & 9,2 & 10,5 & 5 & 7,9 & 8,2 & 7,0 & 7,0 & 7,4 & 8,9 & 11,5 \\
\hline & 2 & & 10,1 & 7,0 & & & & 9,8 & & & & & & & 8,1 & 11,1 & & 7,0 & 6,1 & & 6,8 & 7,3 & 9,6 & 11,6 \\
\hline Agosto & 3 & & 7,9 & 5,0 & 7,1 & 7 & & 6,7 & 8,4 & 11,1 & 10,7 & 5 & & 9,6 & 7,8 & 0 & 7 & 7,9 & 6,3 & 7,2 & 5,5 & 6,1 & 8 & 11,1 \\
\hline & 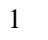 & & & 7,5 & 7,1 & 10,5 & & & & & 12,3 & & 7,3 & 10,3 & 7,5 & 10,3 & & 8,2 & 8,3 & 9,1 & 10,2 & 7,3 & 8,4 & 12,3 \\
\hline & 2 & & & 6,6 & & & 10 & & 10,0 & & 10,9 & & & & & & & 7,0 & 7,9 & & 7,8 & 8,5 & 8,9 & 10,9 \\
\hline Sete & 3 & & 6,5 & 9,4 & 10,5 & ) & & 10,0 & 9,1 & 10,2 & 87 & 7,0 & & 8,6 & 7 & 8,5 & 4,8 & 7,6 & 5,9 & 7,4 & 6,8 & 5,1 & 7,2 & 10,5 \\
\hline & 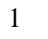 & & 6,6 & 5,9 & & & & & & & 8,5 & 5 & 7 & 7,6 & 7,3 & & 9,6 & 5,5 & 7,6 & 5,4 & 6,8 & 7,4 & 7,4 & 9,6 \\
\hline & 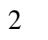 & & 6,3 & 8,0 & & & & & & & 9,4 & & & & 6,8 & & 6,0 & 6,1 & 6,4 & & 5,7 & 7,8 & 7,2 & 9,4 \\
\hline Outubro & 3 & & 6,1 & 6,6 & & & & 7,0 & & & 9,7 & 4,9 & & 9,1 & 7,0 & & 6,3 & 5,9 & 5,3 & & 5,2 & 6,7 & 8,1 & 9,7 \\
\hline & 1 & & & 7,8 & & & & 5,0 & & 9 & 10,2 & 5 & & & 7,3 & 7 & 7,3 & 6,6 & 7,4 & 6,1 & 6,3 & 4,7 & 8,0 & 10,2 \\
\hline Novembro & 2 & & 4,3 & 5,8 & & 5 & 5 , & 5 & 6,1 & 6,7 & 10,1 & 3 & 5,5 & 8,5 & 5,9 & 4,9 & 5,4 & 6,3 & 5,6 & 4,3 & 4,7 & 5,0 & 6,9 & 10,1 \\
\hline Novembro & 3 & & 5,0 & 6,5 & 5,2 & 6,4 & & 4,7 & 7,6 & & 9,6 & 4,7 & 5,4 & 7,8 & 4,7 & 7,6 & 3,7 & 5,3 & 4,7 & 5,0 & 3,5 & 4,2 & 5,5 & 9,6 \\
\hline & 1 & & 5,9 & 5,0 & 6,7 & & & & & 8 & 9,3 & 4, & 5,9 & 6,9 & 4,5 & 5,7 & 5,6 & 5,8 & 4,4 & 6,3 & 4,7 & 6,6 & 6,1 & 9,3 \\
\hline & 2 & 4,5 & 3,9 & 4,8 & 5,5 & 5,6 & & 6,1 & 5 , & 8, & 8,0 & 4, & & 7,6 & 5,1 & 4,8 & 4,8 & 5,8 & 3,9 & 3,6 & 3,7 & 4,1 & 6,7 & 8,2 \\
\hline Dezembro & 3 & 6,4 & 4,8 & 5,8 & 6,9 & 6,7 & 6,9 & & 4,6 & 8,4 & 9,9 & 3,8 & 5,2 & 8,9 & 5,4 & 5,3 & 4,1 & 5,7 & 5,3 & 4,7 & 4,2 & 5,9 & 4,8 & 9,9 \\
\hline Máximo & & 11,3 & 10,1 & 9,4 & 10,5 & 11,0 & 10,5 & 10,0 & 10,9 & 11,9 & 12,3 & 7,3 & 10,3 & 11,5 & 9,2 & 12,0 & 11,8 & 8,7 & 9,0 & 9,1 & 10,2 & 8,5 & 9,6 & 12,3 \\
\hline
\end{tabular}

caracterizado pela presença de maior variabilidade, e como conseqüência, maior tamanho de amostra. Os demais nove locais (Santa Maria, São Borja, Veranópolis, Farroupillha, Erechim, Cruz Alta, Ijuí, Encruzilhada do
Sul e Santa Rosa) formaram o grupo dois, e, estão em situação intermediária. Esses resultados confirmam presença de variabilidade espacial do tamanho de amostra. 


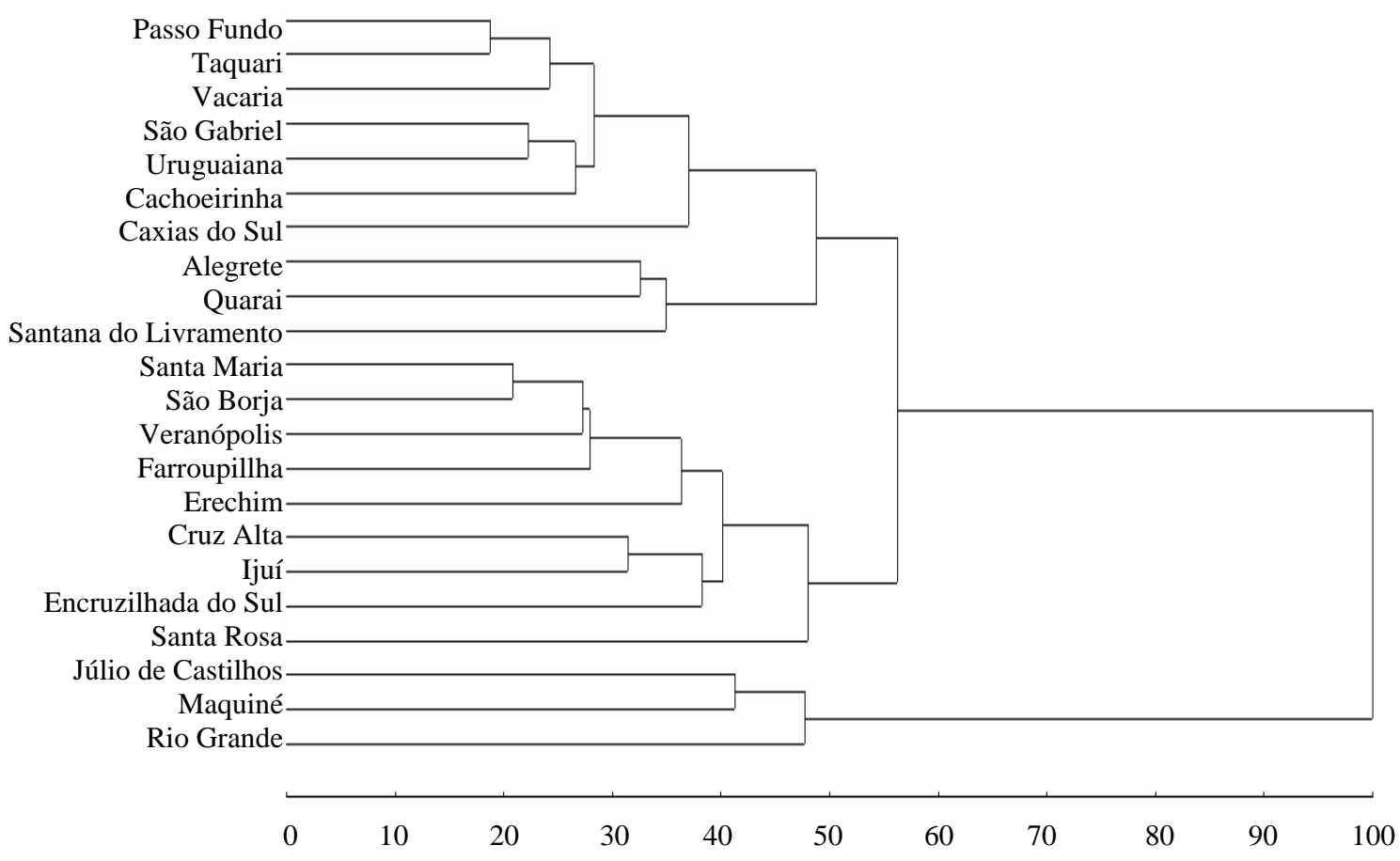

FIGURA 2 - Dendrograma da dissimilaridade, de radiação solar global média decendial, entre 22 locais do Estado do Rio Grande do Sul, obtido pelo método de agrupamento "vizinho mais distante" baseado na distância euclidiana média padronizada.

Esses resultados indicam que 46 anos de observações são suficientes para estimar a radiação solar global média decendial, para uma semi-amplitude do intervalo de confiança igual a $0,10 \hat{\mu} \mathrm{cal} \mathrm{cm}^{-2} \mathrm{dia}^{-1}$, com coeficiente de confiança de $95 \%$. Portanto, as estimativas de séries históricas desses locais, baseadas em menos de 30 anos de observações, possuem uma semi-amplitude do intervalo de confiança menor ou maior que 0,10 , com coeficiente de confiança de $95 \%$ (Tabela 3). A semiamplitude do intervalo de confiança em \% da estimativa da média $(\mu)$ de radiação solar global decendial com coeficiente de confiança de $95 \%$, baseado em uma amostra de 30 anos, oscilou de 3,1\% ( $2^{\circ}$ decêndio do mês de março em Santana do Livramento) a 12,3\% ( $1^{\circ}$ decêndio do mês de setembro em Maquiné) (Tabela 3). Portanto, pode-se inferir com $95 \%$ de confiança que com o uso 30 anos de observações o erro máximo na estimativa da média $(\mu)$ de radiação solar global média decendial será $12,3 \%$ de $\hat{\mu} \mathrm{cal} \mathrm{cm}^{-2} \mathrm{dia}^{-1}$, independentemente do decêndio e local.

De maneira geral, ao usar 30 anos de observações para estimar a radiação solar global média decendial, a precisão da estimativa nos meses de junho, julho, agosto e setembro é menor em relação aos demais meses do ano.

\section{CONCLUSÕES}

Há variabilidade do tamanho de amostra (número de anos) para a estimativa de radiação solar global média decendial no Estado do Rio Grande do Sul no tempo (decêndios) e no espaço (locais). Maior tamanho de amostra é necessário nos decêndios dos meses de junho, julho, agosto e setembro em relação aos outros meses. Para os locais e decêndios estudados, 30 anos de observações são suficientes para estimar a média $(\mu)$ de radiação solar global média decendial, em cal cm $\mathrm{cm}^{-2} \mathrm{dia}^{-1}$, para um erro de estimação igual a $0,123 \hat{\mu}$, com coeficiente de confiança de $95 \%$.

\section{AGRADECIMENTOS}

Os autores agradecem aos pesquisadores, técnicos, observadores meteorológicos, estagiários e demais pessoas que de alguma forma contribuíram para a realização deste trabalho. 


\section{REFERÊNCIAS BIBLIOGRÁFICAS}

BARBETTA, P. A. et al. Estatística para cursos de engenharia e informática. São Paulo: Atlas, 2004. $410 \mathrm{p}$.

BURIOL, G. A.; ESTEFANEL, V.; ANDRIOLO, J. L.; MATZENAUER, R.; TAZZO, I. F. Disponibilidade de radiação solar para o cultivo do tomateiro durante o inverno no Estado do Rio Grande do Sul. Pesquisa Agropecuária Gaúcha, Porto Alegre, v. 6, n. 1, p. 113-120, 2000.

BURIOL, G. A.; HELDWEIN, A. B.; ESTEFANEL, V.; MATZENAUER, R.; MARCON, I. A. Probabilidade de ocorrência de valores de radiação solar prejudiciais ao cultivo do pepineiro na região do baixo vale do Taquari, RS. Pesquisa Agropecuária Gaúcha, Porto Alegre, v. 7, n. 1, p. 97-104, 2001.

BUSSAB, W. O.; MORETTIN, P. A. Estatística básica. 5. ed. São Paulo: Saraiva, 2004. 526 p.

CARGNELUTTI FILHO, A.; MATZENAUER, R.; MALUF, J. R. T. Variabilidade temporal e espacial do tamanho de amostra da temperatura mínima do ar no Rio Grande do Sul, Brasil. Ciência Rural, Santa Maria, v. 36, n. 4, p. 11561163, 2006a.

CARGNELUTTI FILHO, A.; MATZENAUER, R.; MALUF, J. R. T. Variabilidade temporal e espacial do tamanho de amostra para estimativa das médias mensais de temperatura máxima do ar no Estado do Rio Grande do Sul. Revista Brasileira de Agrometeorologia, Piracicaba, v. 14, n. 1, p. 87-95, $2006 \mathrm{~b}$.
CARGNELUTTI FILHO, A.; MATZENAUER, R.; TRINDADE, J. K. Ajustes de funções de distribuição de probabilidade à radiação solar global no Estado do Rio Grande do Sul. Pesquisa Agropecuária Brasileira, Brasília, v. 39, n. 12, p. 1157-1166, 2004.

COSTA-NETO, P. L. O. Estatística. 2. ed. São Paulo: E. Blücher, 2002. 266 p.

CRUZ, C. D. Programa Genes: versão Windows: aplicativo computacional em genética e estatística. Viçosa: UFV, 2001. 648 p.

CRUZ, C. D.; REGAZZI, A. J. Modelos biométricos aplicados ao melhoramento genético. 2. ed. Viçosa: UFV, 1997. $390 \mathrm{p}$.

FONSECA, J. S.; MARTINS, G. A. Curso de estatística. 5. ed. São Paulo: Atlas, 1995. 317 p.

MUNIZ, J. A.; ABREU, A. R. Técnicas de amostragem. Lavras: UFLA/FAEPE, 1999. 102 p.

ROSENBERG, N. J. Microclimate: the biological environmet. New York: J. Wiley \& Sons, 1974. 315 p.

SLATER, P. N. Remote sensing, optics and optical systems. Massachussets: Addison-Wesley, 1980. 575 p.

SPIEGEL, R. A.; SCHILLER, J.; SRINIVASAN, R. A. Probabilidade e estatística. 2. ed. Porto Alegre: Bookman, 2004. 398 p.

STEEL, R. G. D.; TORRIE, J. H. Principles and procedures of statistics a biometrical approach. 3. ed. Nova York: McGraw-Hill, 1997. 666 p. 